\title{
Estrategias de \\ búsqueda de empleo en Trinidad y Tabago
}

\section{Kathleen Valtonen \\ Departamento de Gobierno, Sociología y Trabajo Social, The University of the West Indies, Barbados kvaltonen@uwichill.edu.bb}

Los niveles nacionales de desempleo en Trinidad y Tabago han permanecido altos desde los años ochenta, debido a la recesión económica, las medidas ulteriores de ajuste estructural y la disminución de actividades tradicionales con uso intensivo de mano de obra, como la agricultura de plantación. Los grupos que habían dependido del empleo ocasional disponible en épocas previas a la recesión han venido experimentando un desempleo crónico; combinan empleos ocasionales extremadamente irregulares con actividades en el sector informal y ocupan una posición marginal y precaria en el mercado laboral. Este artículo examina cómo difieren las características y estrategias de las personas que buscan empleo en las áreas centrales (dinámicas) y en las periféricas del mercado laboral. En el análisis de los datos cualitativos, basado en 45 entrevistas en profundidad, se emplearon los procedimientos comparativos cualitativos de Ragin. Este método permitió examinar las combinaciones de características de diferentes individuos e identificar aquellos componentes de su estrategia de búsqueda de empleo que los llevaron a encontrar empleo o que culminaron en desempleo de largo plazo. Los desempleados crónicos mostraron una falta consistente de conocimiento actualizado sobre el mercado laboral, mientras que los que encontraron trabajo disponían de este tipo de información gracias a "lazos débiles" basados en vínculos familiares y otros establecidos previamente con el mercado laboral. El acceso al empleo de individuos que carecían de enseñanza secundaria superior y formación técnico-profesional podría asociarse con sus "lazos de mérito" adquiridos por la experiencia en el empleo y una trayectoria laboral en el sector formal. Los datos sugieren que mientras la afiliación con la economía formal podría fortalecer la posición del individuo en el mercado laboral, la asociación con el sector informal no parecía conducir a ventaja ulterior alguna en ese sentido. 


\section{I}

\section{Introducción}

El trabajo es una parte inextricable de la estructura de las sociedades y es de importancia vital en aquellas que carecen de un sistema de seguridad social amplio. El ingreso depende de la participación en el mercado laboral, y las familias dependen de las remuneraciones de sus miembros económicamente activos. Aunque tradicionalmente el Gobierno de Trinidad y Tabago ha mostrado un fuerte compromiso con la provisión de una red básica de seguridad que cubra a los ancianos, los inválidos y los hogares con jefatura femenina, los ciudadanos "aptos" tienen que depender de sus vínculos con el mercado laboral, puesto que no reúnen los requisitos para recibir las formas tradicionales de asistencia social y no están cubiertos contra el riesgo de desempleo. Los niveles nacionales de desempleo han permanecido consistentemente elevados desde los años ochenta, debido a la recesión, las medidas ulteriores de ajuste estructural y la disminución de las actividades tradicionales que hacen uso intensivo de mano de obra, como la agricultura de plantación. En un ambiente económico difícil, las oportunidades de empleo ocasional que antes abundaban - por ejemplo, en el sector de la construcción pública y privada- se volvieron escasas. Aquella parte de la fuerza laboral que dependía de ese empleo periódico quedó sin medios de subsistencia y ha tenido que buscar oportunidades de ingreso en el sector informal.

En este estudio cualitativo se examinan las características y las estrategias de búsqueda de empleo de grupos desempleados en Trinidad. La entrevista en profundidad es un instrumento que produce una abundancia de datos cuyo escrutinio da información sobre los aspectos de la búsqueda de empleo relevantes en el contexto de esta investigación. Se ha utili- zado una matriz basada en esos aspectos para organizar o "codificar" los datos relativos a la combinación de características y componentes de la estrategia de búsqueda de empleo de cada individuo que haya conducido a acceder a empleo o haya desembocado en desempleo de largo plazo. Se utiliza el álgebra booleana para facilitar la identificación y comparación de las diferentes combinaciones de características y estrategias asociadas con el éxito o el fracaso en la búsqueda de empleo. El estudio abarcó candidatos de niveles socioeconómicos medios bajos y bajos. Entre estos últimos, sobre todo, la formación educacional era débil.

La recopilación de datos apuntó a individuos que se hallaban en diferentes posiciones frente al mercado laboral. El primer grupo incluyó a aquellos que estaban buscando empleo en el área más dinámica del mercado laboral y que se hallaban muy próximos a acceder a él. El segundo grupo estuvo compuesto de individuos que habían estado desempleados por largos períodos y que ocupaban una posición marginal en el mercado laboral. En la investigación se examinó de qué manera difieren las características y estrategias (denominadas en lo sucesivo "los atributos") de los candidatos en las áreas dinámicas y periféricas del mercado laboral en Trinidad. La tipología que emerge de este ejercicio puede ser útil para la planificación de políticas e intervenciones con miras a grupos similares en riesgo de quedar marginados de la fuerza laboral. Lo que se busca es una visión holística de la gama de atributos principales y sus procesos de interrelación. En el caso de los grupos marginados, los problemas suelen tener que abordarse en varios frentes para que las soluciones sean eficaces.

\section{II}

\section{El mercado laboral: el centro y la periferia}

Trinidad y Tabago (con una población de 1.4 millones de habitantes) es uno de los Estados insulares del Caribe con un pasado colonial y una era más reciente de independencia que comienza a principios de los años sesenta. La historia de colonización y desarrollo ha dado a cada isla caribeña su propio carácter. La isla de Trinidad se distingue por sus recursos de petróleo y gas natural. Sus exportaciones de petróleo constitu- 
yen sólo una pequeña fracción de la producción mundial total, pero son la principal fuente de ingreso del país. La economía depende sobremanera de la producción y exportación de petróleo y gas. Este sector, que hace uso intensivo de capital, es muy sensible a las fluctuaciones de precios en el mercado mundial (Rogozinski, 1994, pp. 275-279).

Las ganancias imprevistas del petróleo en el período comprendido entre 1973 y 1982 posibilitaron el aumento del ingreso, la expansión de las ocupaciones en el sector público y de las inversiones en infraestructura y el mejoramiento de las condiciones de vida. ${ }^{1}$ Con la caída de los precios internacionales del petróleo durante los años ochenta, hubo una brusca contracción de la economía, y no pudieron mantenerse los altos niveles de gasto del gobierno. Mientras tanto, sólo un reducido número de los empleos que se habían creado estaba en el sector productor de bienes durables, e incluso en la cúspide del auge del petróleo la tasa de desempleo no bajó mucho de $10 \%$. Durante la recesión, y con las medidas restrictivas que requirió el ajuste estructural, habían disminuido los trabajadores en el sector público. Los programas de obras públicas de infraestructura, de los que muchos habían llegado a depender como fuente periódica de ingreso, también se habían restringido. En la industria de la construcción, la declinación de los sectores público y privado significó una caída - tras el apogeo de 1980, cuando empleaba a $18 \%$ de la fuerza laboral- a una situación en que la mitad de la fuerza laboral del sector quedó desempleada a fines de los años ochenta (Naciones Unidas, 1995; Ramsaram, 1992). Los individuos no calificados vieron disminuir sus posibilidades de ganarse la vida tanto en los proyectos de obras públicas como en el sector de la construcción, lo que acarreó penurias económicas a las familias que habían dependido de este tipo de trabajo. Esta situación se reflejaba en las condiciones de vida de los desempleados con menos educación del grupo considerado.

La tasa de desempleo fluctuó entre 16 y $22 \%$ en los años noventa. En el tercer trimestre de 1995, según datos de la Oficina Central de Estadística, dicha tasa fue de $16.3 \%$, la más baja desde 1985. La desocupación era mayor entre las mujeres y la juventud. En Trinidad y Tabago, el desempleo está vinculado muy

\footnotetext{
${ }^{1}$ El gasto público y los subsidios a la producción aumentaron en la administración pública, en particular, y en las transferencias que se expandieron para aliviar las altas tasas de desempleo sostenidas que se atribuían a que el sector petrolero se caracterizaba por hacer uso intensivo de capital (Banco Mundial, 1995, pp. 11-32).
}

estrechamente con la desigualdad económica y social. Según Henry y Melville (1989), la correlación entre el desempleo y la pobreza era de 0.88 a fines de los años ochenta.

Más de $75 \%$ de todos los trabajadores están empleados en el sector formal: el sector formal privado emplea a $42 \%$ y el sector público a $33 \%$. El resto de la fuerza laboral se ubica en el sector informal y contiene una porción significativa de trabajadores por cuenta propia (autónomos). El sector agrícola ocupa menos de 5\% de la fuerza laboral. Las ocupaciones no son significativamente distintas en los sectores rurales y urbanos.

Ciertas áreas de trabajo no calificado que van en aumento, tales como los empleos domésticos y de seguridad (empleadas domésticas y guardias), tienen niveles elevados de subempleo. El sector informal ${ }^{2}$ es el área del mercado laboral al que los individuos recurren en último término en búsqueda de una oportunidad de obtener ingreso. La economía informal es mirada desde dos ángulos: como factor que refuerza la desigualdad social o como factor que sirve para aliviar o diluir las condiciones de desigualdad (véase McKeever, 1998). ${ }^{3}$ El trabajo en el sector informal comprende servicios personales, producción de artesanías y pequeños negocios (incluidas las microempresas). Los salarios en el sector informal equivalen en promedio a la mitad de los que perciben los trabajadores manuales y no manuales en la empresa moderna (CEPAL, 1997, p. 16).

Los datos recopilados revelaron que el establecimiento de redes sociales informales, basadas en una fuerte reciprocidad, y el ingreso intermitente que a

\footnotetext{
${ }^{2}$ De conformidad con el uso más aceptado del término, la "economía informal" se refiere a las formas lícitas de generación del ingreso que no están reguladas por las instituciones legales y políticas de la sociedad (Portes y Castells, 1989, p. 12). Por ejemplo, los trabajadores no pagarían impuestos, los lugares de trabajo no cumplirían con las ordenanzas gubernamentales o los propietarios de negocios operarían sin las licencias exigidas. Este tipo de actividad económica se da, sin embargo, dentro del contexto de una economía formal dominante, y no en forma independiente de esa economía. Además, generalmente hay vínculos entre ambas: por ejemplo, entre ellas circulan materiales, trabajo y productos terminados (McKeever, 1998, p. 1211).

${ }^{3}$ En estudios más recientes se aduce que la economía informal comprende una amplia gama de ocupaciones, las que ofrecen oportunidades a muchos que no las tendrían en el sector formal, pero que al mismo tiempo explotan el trabajo de otros. En el análisis que hizo McKeever (1998) de los datos de encuestas efectuadas en Sudáfrica a nivel nacional, se observó que el éxito, en términos de posición ocupacional y logros de ingreso, sigue patrones de estratificación en la economía informal que son consistentes con los de la economía formal.
} 
menudo proviene del sector informal, conforman los mecanismos más comunes de subsistencia en círculos que carecen de ingreso regular. Las familias libran una lucha cotidiana por solventar incluso los gastos esenciales, como los de alimentos, medicamentos, vestuario o transporte para los hijos en edad escolar. La subsistencia económica en las redes informales ha llegado a ser un mecanismo de supervivencia permanente para los desempleados y subempleados crónicos. La asistencia mutua es la única "red de seguridad" existente, que puede ocasionalmente complementarse con programas de asistencia social como el que nos permitió contactar a los desempleados crónicos del grupo estudiado. Muchos individuos desempleados buscan trabajo de una $u$ otra índole en la economía informal. La venta ambulante de alimentos y pequeños artículos, o entre los de raigambre rural la venta de productos caseros, son algunas de las formas de generar ingreso.

\section{III}

\section{Estudios previos}

La dinámica económica y estructural de la desigualdad social en el Caribe ha sido objeto de varios estudios, entre otros los de Ramsaran (1992) y Gafar (1998). Los aspectos sociopolíticos y raciales de la desigualdad han sido investigados por Ryan y Stewart (eds., 1995). Dentro del marco de la pobreza y la privación, las características de los grupos más necesitados han sido estudiadas por Ryan, McCree y St. Bernard (eds., 1997), quienes utilizaron encuestas cuantitativas y datos de entrevistas. Estos aspectos también figuran en el trabajo de Valtonen (1996) sobre la integración de los inmigrantes en Trinidad, y en el estudio minucioso de Neil (1987) sobre una determinada comunidad local en el sector urbano de Trinidad.

En la región caribeña no ha habido investigación de las estrategias de empleo ni de las etapas de búsqueda de empleo en el proceso de participación en el mercado laboral. En este artículo se examina una etapa preliminar, pero crucial, en el umbral del mercado de trabajo en que los individuos negocian la entrada o reentrada al empleo.

\section{IV}

\section{La recopilación de datos y el grupo escogido}

El presente estudio está basado en datos cualitativos provenientes de entrevistas en profundidad realizadas en Trinidad ${ }^{4}$ en 1995-1997. Cada entrevista duraba entre una hora y una hora y media. Las entrevistas estaban semiestructuradas en torno a temas que eran abordados mediante preguntas directas, y también mediante sondeos. Los individuos estaban dispuestos a participar en el estudio porque el tema era motivo de preocupación, tanto para ellos como para otros en la misma situación.

\footnotetext{
${ }^{4}$ La mayoría de la población vive en Trinidad donde también está situado el sector industrial "moderno". El estudio al que se refieren los datos del artículo se realizó en Trinidad. En Tabago, donde vive $3.3 \%$ de la población, la agricultura es la ocupación principal, con alguna diversificación hacia el turismo.
}

Los encuestados fueron 45 , con edades que fluctuaban entre 17 y 45 años. 22 eran de origen urbano provenientes de Puerto España y sus alrededores, y 23 de origen rural. 24 sujetos sólo tenían educación primaria. De los 21 sujetos que tenían alguna educación secundaria, 10 habían cursado sólo el primer ciclo de ella. Dos de estos últimos habían continuado hasta completarla y habían egresado de la escuela secundaria. ${ }^{5}$ En general

\footnotetext{
${ }^{5}$ Los grados primero a quinto (grupo etario de 5 a 11 años) corresponden a la enseñanza primaria; la enseñanza secundaria consta de un primer ciclo de cinco grados (grupo etario de 12 a 16 años) al término del cual se rinde el examen de nivel O., y de un sexto grado - superior e inferior-, que atiende al grupo etario de 17 a 18 años y conduce al examen de nivel A. Cabe señalar que 55\% de la población económicamente activa de Trinidad y Tabago sólo ha cursado los años iniciales de la enseñanza secundaria.
} 
el grupo exhibía logros educacionales, pero en la mayoría éstos eran de nivel bajo (primario y secundario inferior).

Siguiendo el procedimiento del método cualitativo, se hizo un muestreo deliberado para llegar a los individuos que mejor podían suministrar información sobre el tema que se investigaba. El grupo seleccionado se extrajo de dos áreas del mercado laboral, y comprendió individuos que estaban buscando empleo en el sector dinámico del mercado laboral y a punto de acceder a él e individuos que habían estado desempleados por largo tiempo y carecían de toda posibilidad inmediata de hallar trabajo. Este procedimiento de muestreo permitió diferenciar en el grupo seleccionado por resultado de la estrategia y facilitó la comparación de las configuraciones de atributos.

Los sujetos que estaban a punto de acceder a una ocupación fueron contactados por intermedio de la Oficina Estatal del Trabajo. ${ }^{6}$ Algunos se hallaban en la etapa de preselección para desempeñar labores de oficina en el sector público y era probable que fueran llamados de inmediato o dentro de poco a llenar las vacantes. Otros se estaban inscribiendo para obtener empleo en la cosecha de frutas en Canadá, que es una actividad de contratación estacional organizada por las autoridades laborales.
Los individuos con una posibilidad de empleo más remota fueron contactados mediante el programa de alimentación complementaria de una organización no gubernamental (ONG) que funciona bajo los auspicios del Estado. El requisito para acogerse a él es la incapacidad de sufragar la canasta mínima de alimentos. ${ }^{7}$ El programa suministra asistencia alimentaria a los hogares seleccionados por un período de tres meses. En su calidad de participantes de este programa de asistencia social de nivel residual y altamente focalizado, estos hogares venían experimentando dificultades económicas y desempleo por un número considerable de años. Los datos, por lo tanto, se obtuvieron de dos grupos del espectro de los que buscan empleo, uno que despliega una estrategia de empleo eficaz y el otro que aplica una estrategia ineficaz.

El protocolo de la entrevista estaba estructurado en las siguientes secciones: información personal (edad, estado civil, familia y tipo de hogar); nivel de educación (escolaridad y enseñanza profesional); historia laboral (tipos de actividad, empleadores, duración de los períodos de empleo, búsqueda de ocupación, canales, contactos); visión propia del futuro, proyectos, sugerencias para intervenciones oficiales.

\section{V}

\section{Marco conceptual}

El marco teórico y conceptual experimentó algunos cambios en el curso de la recopilación y el análisis de datos, cosa que es común en el método cualitativo. ${ }^{8}$ En esta sección se analiza el marco teórico elaborado con la gama de atributos y estrategias de búsqueda de empleo que, según los datos, tuvieron un impacto sobre el proceso de búsqueda de empleo en el grupo estudiado.

La tesis de Bourdieu relativa al efecto de la transmisión cultural sobre el éxito ocupacional ulterior en la generación siguiente tiene importancia para este estudio. Bourdieu y Passeron (1977) sostienen que la educación reproduce el sistema de estratificación social, puesto que el capital económico de los padres

\footnotetext{
${ }^{6}$ El Estado no mantiene servicios integrales de colocaciones e información laborales (bolsas de trabajo), pero efectúa contrataciones para determinadas áreas de empleo en el sector público, y con menor frecuencia en el sector privado.
}

puede transformarse en el "capital cultural" de los hijos, el que a su vez determina la posición económica y el éxito ocupacional de la segunda generación. Según Bourdieu, cada clase posee su propio conjunto de significados, o marco cultural, que es internalizado inicialmente mediante la socialización en el seno de la familia. Este habitus moldea la percepción, el pensamiento, el gusto, la apreciación y la acción. Al mismo tiempo, es un marco de significados que la clase

\footnotetext{
7 Se estima que $11 \%$ de los hogares en Trinidad y Tabago son "extremadamente pobres", es decir, incapaces de acceder a la canasta mínima de alimentos (Naciones Unidas, 1995).

${ }^{8}$ Ragin (1994, p. 82) sostiene que la investigación cualitativa suele entrañar un proceso de aclaración recíproca de la imagen que tiene el investigador del tema investigado, por una parte, y de los conceptos que enmarcan la investigación, por otra. Las imágenes se construyen a partir de casos, a veces mediante la búsqueda de similitudes entre varios ejemplos del fenómeno que parecen pertenecer a la misma categoría general. A su vez, estas imágenes pueden relacionarse con conceptos.
} 
dominante está en condiciones de imponer a las demás (y en el sistema educativo) como la única cultura legítima. Así, los hijos de las familias de las clases altas están equipados con un "capital cultural" que promueve sus logros académicos y su éxito ocupacional definitivo. En general, se supone que este proceso de transmisión cultural, que subyace a la actividad orientada al logro, está ausente en los niveles inferiores de la estructura social, donde se supone que los individuos están en desventaja frente a sus contrapartes de la clase "superior".

Aunque el grupo seleccionado no provenía de los niveles asociados generalmente con los procesos de transmisión cultural de Bourdieu, los datos mostraron que la mayoría de los sujetos estaban, empero, muy conscientes del valor y la utilidad de la educación. No obstante, a menudo su carrera escolar se había interrumpido prematuramente porque sus familias o su origen habían sido demasiado pobres para costear los gastos de libros, transporte, uniformes, etc., que el caso requería. ${ }^{9}$ Esta era una característica prevalente entre los que habían iniciado la educación secundaria, pero la habían abandonado antes de completar su primer ciclo. Su precaria formación educacional no se debió tanto a estar fuera de los círculos donde se suponía que ocurría la transmisión cultural, sino más bien a circunstancias materiales que inhibían la continuación de sus estudios. Esta conclusión corrobora la de Halsey, Heath y Ridge (1980), cuyo estudio de los alumnos de una escuela secundaria selectiva halló que las circunstancias materiales eran un factor que determinaba la duración de la carrera escolar.

Al considerar el grupo en estudio conviene examinar los vínculos entre el nivel educativo y la posición en el mercado laboral desde una perspectiva familiar. Los sujetos situados en el extremo superior de la escala educativa, que habían completado efectivamente la enseñanza secundaria, venían de familias en que al menos un adulto tenía empleo estable en el sector formal. Entre los sujetos cuya educación se había interrumpido, los vínculos familiares con el mercado laboral tendían a ser mucho más tenues. El logro educacional sostenido en este grupo parece estar vinculado, en general, con una posición socioeconómica relativamente más firme. La teoría de la transmisión cultural puede tener también aplicación en los estratos socioeconómicos medio bajo y bajo. Mientras que en los niveles superiores de la estructura social los antecedentes familiares o el "capital cultural" y el mayor

\footnotetext{
${ }^{9}$ Las donaciones de libros y uniformes que antes se destinaban a
} las familias pobres se suspendieron durante la recesión económica. logro académico conducentes al éxito ocupacional están presumiblemente vinculados, en los niveles inferiores el mero hecho de completar la educación básica puede ser la vía que permite salir de la dependencia económica o de condiciones de subsistencia.

El concepto de "recursos sociales" involucra una gama de componentes tangibles e intangibles. Es posible seleccionar aspectos que puedan aplicarse al grupo estudiado cuyo respaldo en recursos educativos y familiares es más débil. Los recursos sociales han sido definidos en función de la riqueza, la posición social, el poder y los lazos sociales de las personas que están vinculadas directa o indirectamente con el individuo. Lin, Ensel y Vaughn (1981) postularon que el acceso a los recursos sociales y su utilización a través de la red propia del individuo ofrece una transición esencial entre los antecedentes familiares y la educación, por una parte, y el logro socioeconómico, por la otra. $\mathrm{Su}$ estudio se centró en un aspecto de los contactos personales, a saber, la posición ocupacional del contacto utilizado en la búsqueda de empleo. Tomando en cuenta las restricciones metodológicas derivadas del uso de un solo aspecto de los recursos sociales, los datos sugirieron que el individuo que tiene acceso a mayores recursos sociales y los utiliza, posee una ventaja considerable en el proceso de búsqueda de empleo ( $i b i d$., p. 1176). Los recursos sociales son considerados como atributos intermediarios, que median entre los recursos personales y el logro de la posición ocupacional. El modelo de Lin, Ensel y Vaughn (1981) propone concretamente que las características (socioeconómicas) de los contactos personales influyen en el nivel de la posición ocupacional que se alcanza.

El presente análisis se ocupa de dos aspectos de los recursos sociales que, conforme indican los datos, revisten importancia para el proceso de búsqueda de empleo y sus resultados. Se identificaron dos categorías de lazos sociales, los "lazos débiles" (Granovetter, 1973) y los "lazos de mérito".

Granovetter sostiene que la mayoría de los modelos de redes se ocupan de los lazos fuertes, ${ }^{10}$ cir-

\footnotetext{
${ }^{10}$ Granovetter (1973) postula que la fuerza de un lazo es una combinación (probablemente lineal) de la cantidad de tiempo, la intensidad emocional, la intimidad (confianza mutua) y los servicios recíprocos que lo caracterizan. Los antropólogos asocian a los lazos fuertes con los contenidos múltiples (multiplexity) en una relación (véase Kapferer, 1969, p. 213). Marsden y Campbell (1984) observaron en un estudio de lazos entre mejores amigos que los indicadores óptimos de un concepto no observado de lazo fuerte eran las medidas de cercanía o intensidad, ya que no estaban contaminadas por otras medidas. La duración tendía a exagerar la fuerza de las relaciones de parentesco y la frecuencia exageraba la fuerza de los lazos con los compañeros de trabajo y vecinos. La frecuencia tenía una asociación muy escasa con la cercanía y la duración.
} 
cunscribiendo su aplicabilidad a grupos pequeños bien definidos, con lo cual se pasan por alto todos los aspectos importantes que entraña su contenido. Hace hincapié en los "lazos débiles" que funcionan como mecanismos de enlace con lo externo, y especialmente entre grupos. Estos son cauces por los cuales las ideas, influencias o información socialmente alejadas del individuo pueden llegar a él. Mientras menores sean los contactos indirectos que tenga una persona, más aislada estará en términos de conocer el mundo más allá de su propio círculo de amistades. El grado de superposición de las redes de amistad de dos individuos varía también directamente con la fuerza de los lazos diádicos (Granovetter, 1973, pp. 1370-71).

En este estudio se entiende que los "lazos débiles" son aquellos que carecen de las características de los lazos fuertes, pero se destaca especialmente su función como vías de información nuevas a las que el individuo que busca empleo no tendría acceso normalmente a través de los lazos fuertes de su red de interacción inmediata, pero generalmente limitada. Los "lazos débiles" pueden incluir también lazos indirectos que pueden transmitirse a través de otros, y también lazos directos flexibles, en que la interacción no se sostiene en forma intensiva.

Del examen de los datos surgió una categoría de recursos sociales denominada "lazos de mérito", que se refiere a los vínculos con el mercado laboral que se han establecido gracias al esfuerzo propio del individuo. El mérito se refiere también al valor asignado por otros. Los "lazos de mérito" están basados en el logro o desempeño previo del individuo en alguna esfera. Es el reconocimiento, reputación o mérito generado en dicha actividad y goza de legitimidad en amplios círculos del mercado laboral. Tiene la calidad de "capital simbólico”, que según Bourdieu (1986) es todo ac- tivo social, tangible o intangible, que es considerado legítimo en la sociedad. Esta categoría de lazos del mercado laboral pertenece al tipo de lo "construido", es decir, se trata de vínculos construidos por el individuo con amigos, compañeros de trabajo, empleadores y otros en el curso de su vida laboral y de otras actividades, al contrario de los lazos prescritos de consanguinidad y parentesco por afinidad (véase Lin, Ensel y Vaughn, 1981). Dado que buena parte de la investigación realizada sobre el vínculo entre los recursos personales (antecedentes familiares y educación) y el logro de una posición ocupacional está centrada en los estratos donde cabe suponer que los recursos personales son de peso, los "lazos de mérito" como una forma alternativa de recursos personales son de especial importancia para los estratos socioeconómicos menos favorecidos que aquí se estudian.

Las áreas de interacción humana rara vez son categorías discretas. Los "lazos de mérito" también pueden ser generadores de información y funcionar entonces como "lazos débiles". Estos últimos se consideran esencialmente como generadores de información, por ejemplo, sobre las condiciones existentes en el mercado laboral, que de otro modo no estarían disponibles socialmente para el candidato. Se entiende que los primeros son un activo que goza de legitimidad y valor simbólico en la sociedad. En este estudio se postula que los "lazos de mérito" están basados, por ejemplo, en la trayectoria ocupacional de un individuo en una empresa de prestigio, o la historia de relaciones laborales estables sobre todo en el sector formal, que genera una sensación de confianza en los empleadores potenciales. Los "lazos de mérito" podrían también ser el sinónimo o la significación de un nivel de especialización deseable que se mantiene, o quizá incluso se adquiere y desarrolla, en entornos laborales favorables.

\section{VI}

\section{Características y estrategias de empleo observadas en el grupo estudiado}

En el examen de los datos se seleccionaron de partida las estrategias de empleo y características específicas que ejercían más influencia en el resultado de la búsqueda de ocupación. Estas se transformaron en medi- das a escala nominal para cumplir con los requisitos del álgebra booleana que utiliza datos binarios. Hay dos condiciones o estados: verdadero (o presente) y falso (o ausente), que están representados por 1 que indica 
presencia y 0 que indica ausencia, de los siguientes atributos:

- Antecedentes familiares abreviado a "familia": la presencia de "familia" indica que un adulto de la familia directa o de la familia ampliada ${ }^{11}$ del sujeto tiene un empleo estable. Hay alguna fuente regular de ingreso y tal vez también contactos o "capital social" en el lugar de trabajo. La ausencia significa que el (los) adulto(s) de la familia carece(n) de un empleo estable.

- Educación secundaria abreviada a "secundaria": la presencia de "secundaria" indica que el individuo ha llegado al segundo ciclo de la enseñanza secundaria y que ha aprobado el primero. La ausencia significa que el individuo ha cursado la enseñanza primaria y tal vez los primeros años de la secundaria.

- Enseñanza técnico-profesional abreviada a "técnico-profesional": la presencia de "técnico-profesional" indica que el individuo ha recibido enseñanza técnico-profesional, adquiriendo con ello una especialización que incrementa su empleabilidad. ${ }^{12}$ La ausencia significa que el individuo no ha pasado por esta enseñanza.

- Especialización: la presencia de "especialización" indica que el individuo ha adquirido cierto nivel de especialización, a través de la enseñanza técnico-profesional $\mathrm{u}$ otros conductos, que mejoraría sus posibilidades en el mercado laboral. La ausencia significa que el individuo compite básicamente por trabajo no calificado en el mercado del empleo.

- "Lazos de mérito" abreviado a "mérito": la presencia de "mérito" indica que el individuo ha establecido "lazos de mérito" que lo vinculan con, al menos, una institución o empleador reconocido socialmente. El vínculo es flexible y está basado en un período de participación adecuado o en buenos antecedentes laborales. Los "lazos de mérito" pueden ser también una señal de empleabilidad, pues indican que el individuo ha adquirido cierta especialización en el empleo, y funcionan como una garantía social de competencia o validez. La ausencia significa que el individuo

\footnotetext{
11 Aunque la familia nuclear es la forma que predomina en los hogares de Trinidad y Tabago (40\%), la familia ampliada representa a $21.4 \%$ de los hogares y las familias monoparentales a $13.9 \%$.
}

carece de garantía social que respalde sus iniciativas de búsqueda de empleo a cualquier nivel. Los datos sugieren que los "lazos de mérito" se establecieron principalmente por la participación en el sector formal. La actividad laboral en el sector informal no pareció tener este tipo de valor.

- "Lazos débiles" abreviado a "débiles": la presencia de "débiles" indica que el individuo tiene información sobre, por lo menos, dos áreas posibles de oportunidad de empleo, mediante contactos con redes (en este grupo, tales contactos eran en general indirectos). Por lo tanto, el individuo está al tanto de los acontecimientos en el mercado laboral ampliado y de las posibles áreas de oportunidad, especialmente en el nivel apropiado a su capacidad y potencial. La ausencia significa que la actividad de búsqueda de empleo del individuo era algo dispersa, difusa y tal vez improductiva.

- Urbano: la presencia de "urbano" indica que el sujeto reside en una concentración urbana, donde generalmente no surgen problemas de distancia y costo de transporte en la etapa de búsqueda de empleo. En el caso de los sujetos que viven en el campo, la búsqueda de empleo se vio entorpecida a menudo por la falta de recursos para cubrir los costos de transporte.

- Plan: la presencia de "plan" indica que el individuo proyecta adquirir cierto tipo de capacitación para mejorar su empleabilidad. La ausencia significa que el individuo no está considerando alternativas para mejorar su base de capacidades.

- Búsqueda de trabajo activa abreviada a "activa": la presencia de "activa" indica que el individuo se dedica muy activamente a la búsqueda de empleo, hace indagaciones con gran frecuencia y entabla contactos directos. La ausencia significa que las actividades de búsqueda de empleo son de poca monta, quizá debido también a problemas financieros con el transporte.

Una característica que al principio se pensó que podría ser significativa resultó común a todos los sujetos. Todos declararon que estaban dispuestos a aceptar cualquier tipo de trabajo. Este atributo no se incluye en la matriz.

\footnotetext{
${ }^{12}$ Se emplea el género masculino en la redacción para aligerar la lectura del texto.
} 


\section{VII}

\section{Procedimientos y resultados}

El escrutinio de las combinaciones de características y estrategias se realizó utilizando el análisis comparativo cualitativo y los procedimientos conexos de álgebra booleana desarrollados por Ragin (1987 y 1994). Los aspectos principales de los procedimientos se describen someramente a partir del texto de Ragin.

$\mathrm{El}$ análisis booleano es combinatorio por diseño. Este aspecto de la lógica combinatoria es consistente con la idea de que los casos, especialmente en sus rasgos causalmente relevantes, deben ser considerados en forma holística. Por lo tanto, en la comparación cualitativa de raíz booleana, las causas no se tratan en forma aislada sino siempre dentro del contexto de la presencia y ausencia de otras condiciones causalmente relevantes.

Si se identifican los patrones de similaridades y diferencias es posible identificar los vínculos causales: cómo diferentes configuraciones de causas producen diferentes resultados en la gama de casos. El enfoque booleano tiene varios aspectos que se prestan para el análisis en este estudio. Posee la capacidad de abordar coyunturas causales complejas y permite que el investigador estudie los casos como un todo y también como partes. La organización de las observaciones en la forma de configuraciones que pueden yuxtaponerse hace posible presentar y "evaluar" explicaciones que compiten entre sí.

Se construyó una matriz de datos brutos o "tabla lógica de verdad" para los datos relativos a todo el grupo seleccionado. La tabla lógica de verdad no se presenta aquí en toda su extensión ya que es posible resumir las configuraciones que existen en la matriz de datos brutos indicando el número de veces que ocurrió cada una. El cuadro 1 ofrece un resumen de las configuraciones. Cada renglón del cuadro 1 representa un tipo de configuración, y el número de veces de ocurrencia en el grupo estudiado figura en la última columna.

En el análisis booleano, el número de veces de ocurrencia de cada combinación de condiciones causales no entra directamente en cálculo alguno. Los criterios de frecuencia no son tan importantes como lo son en el análisis estadístico. Lo que interesa son los tipos de situaciones (es decir, los renglones de la tabla lógica de verdad) como la unidad de análisis básica.

Por razones de claridad, las configuraciones se pueden traducir en letras mayúsculas para representar la presencia de la condición, y en letras minúsculas para representar la ausencia de esa misma condición. Así, "SECUNDARIA" indica la presencia de esta condición, y "secundaria" indica su ausencia. El cuadro 2 muestra todas las configuraciones identificadas (que figuran en el cuadro 1), traducidas en nombres con mayúsculas y minúsculas. El signo de multiplicación (•) se utiliza para indicar la combinación de condiciones.

En esta etapa, puede darse el primer paso hacia la minimización, lo que supone combinar los renglones cuando sólo difieren en una condición causal, pero tienen los mismos resultados. Este paso produce configuraciones que Ragin (1987) denominó "implicantes primordiales". Esta estrategia de simplificación sigue la lógica de un experimento. Sólo se permite que varíe una condición (la "condición experimental") a la

CUADRO 1

Resumen de configuraciones

\begin{tabular}{cccccccccccc}
\hline $\begin{array}{c}\text { Renglón } \\
\mathrm{N}^{\circ}\end{array}$ & Familia & Secundaria & Mérito & Débiles & Urbano & Plan & Activa & $\begin{array}{c}\text { Especiali- } \\
\text { zación }\end{array}$ & $\begin{array}{c}\text { Técnico- } \\
\text { profesional }\end{array}$ & $\begin{array}{c}\text { Resultado- } \\
\text { empleo }\end{array}$ \\
\hline 1 & 1 & 1 & 0 & 1 & 1 & 1 & 1 & 0 & 0 & 1 & 7 \\
2 & 1 & 0 & 0 & 1 & 1 & 1 & 1 & 0 & 0 & 1 \\
3 & 0 & 1 & 0 & 1 & 1 & 1 & 1 & 0 & 0 & 1 & 2 \\
4 & 1 & 1 & 0 & 1 & 1 & 1 & 1 & 1 & 1 & 1 & 1 \\
5 & 0 & 0 & 1 & 1 & 0 & 0 & 1 & 1 & 0 & 1 & 5 \\
6 & 0 & 1 & 0 & 0 & 1 & 1 & 1 & 0 & 0 & 0 & 2 \\
7 & 0 & 0 & 0 & 0 & 1 & 0 & 1 & 0 & 0 & 0 & 4 \\
8 & 0 & 0 & 0 & 0 & 0 & 1 & 0 & 0 & 0 & 0 & 1 \\
9 & 0 & 0 & 0 & 0 & 0 & 0 & 0 & 0 & 0 & 0 & 4 \\
\hline
\end{tabular}


Resultado: acceso a empleo

1. FAMILIARES. SECUNDARIA. mérito. DEBILES. URBANO. PLAN. ACTIVA. especialización. técnico-profesional

2. FAMILIARES. secundaria. mérito. DEBILES. URBANO. PLAN. ACTIVA. especialización. técnico-profesional

3. familiares. SECUNDARIA. mérito. DEBILES. URBANA. PLAN. ACTIVA. especialización. técnico-profesional

4. FAMILIARES. SECUNDARIA. mérito. DEBILES. URBANA. PLAN. ACTIVA. ESPECIALIZACION. TECNICO-PROFESIONAL

5. familiares.secundaria. MERITO. DEBILES. urbana. plan.ACTIVA.ESPECIALIZACION. técnico-profesional

Resultado: falta de acceso a empleo

6. familiares. SECUNDARIA. mérito. débiles. URBANA. PLAN.ACTIVA. especialización. técnico-profesional

7. familiares.secundaria.mérito.débiles.URBANA.plan.ACTIVA.especialización. técnico-profesional

8. familiares. secundaria. mérito. débiles. urbana. PLAN. activa. especialización. técnico-profesional

9. familiares. secundaria. mérito. débiles. urbana. plan. activa. especialización. técnico-profesional

a En mayúsculas: presencia de la condición. En minúsculas: ausencia de la condición.

vez. Si la variación de esta condición no tiene un impacto discernible sobre el resultado, ésta puede eliminarse como factor (Ragin, 1994, pp. 124-125).

En los renglones 1 y 2, ambos conducentes al resultado de acceso al empleo, todos los aspectos salvo uno, la educación secundaria, son los mismos. Los individuos pueden estar buscando empleo con eficacia, incluso en ausencia de una educación secundaria superior. No obstante, cabe señalar que la combinación exitosa con la ausencia de secundaria no es común en el grupo seleccionado, y es casi una excepción. Sin embargo, los renglones 1 y 2 pueden parearse, y omitiendo la variable secundaria que no afecta el resultado, el renglón minimizado reza así:

FAMILIA. mérito. DEBILES. URBANO. PLAN.

ACTIVA. especialización. técnico-profesional

No es posible hacer nuevas minimizaciones entre las combinaciones exitosas, puesto que no hay otras combinaciones de pares que difieran sólo en un aspecto. Quedan cuatro configuraciones para describir la diversidad de caracteres y estrategias entre los 17 individuos que están buscando trabajo con eficacia.

En el cuadro 2, en la lista que muestra el resultado negativo (falta de acceso al empleo), los renglones 8 y 9 sólo difieren en la presencia y ausencia de Plan. Ambos renglones pueden parearse y minimizarse omitiendo la variable Plan que no influye en el resultado. El renglón minimizado reza ahora así: familia. secundaria. mérito. débiles. urbano. activa. especialización. técnico-profesional

Los implicantes primordiales presentan configuraciones de atributos sucintos. Las combinaciones de implicantes primordiales establecidas a partir de los datos pueden considerarse como configuraciones de condiciones causales o simplemente como combinaciones de características, que forman la base de una tipología empírica. Dado que el interés principal de este estudio es describir sucintamente la diversidad mediante la determinación de los implicantes primordiales, no fue necesario proseguir con la minimización o los procedimientos de computación. La etapa final de la minimización booleana, el "gráfico de implicantes primordiales", que busca la máxima parsimonia lógica, no se efectuó porque no era ése el objetivo.

La brevedad de la etapa de minimización no es una desventaja en este estudio, ya que la necesaria claridad y economía de descripción se logran mediante la organización de los datos conforme a los procedimientos booleanos que facilitan la identificación de distintas combinaciones.

El álgebra booleana es útil para el análisis de grupos en los cuales la falta de recursos puede tener la misma influencia en determinar el resultado, debido a que los componentes son considerados, en su presencia y también en su ausencia, como parte de las expresiones de los implicantes primordiales. El método permite extrapolar interrelaciones holísticas dentro de las configuraciones. 
CUADRO 3

\section{Una tipología empírica de configuraciones de atributos de individuos que buscan empleo}

Configuraciones con resultado fructífero: acceso a empleo

10. FAMILIARES. mérito. DEBILES. URBANO. PLAN. ACTIVA. especialización. técnico-profesional

11. familiares. SECUNDARIA. mérito. DEBILES. URBANO. PLAN. ACTIVA. especialización. técnico-profesional

12. FAMILIARES.SECUNDARIA.mérito.DEBILES.URBANO.PLAN.ACTIVA. ESPECIALIZACION. TECNICO-PROFESIONAL

13. familiares. secundaria. MERITO. DEBILES. urbano. plan. ACTIVA. ESPECIALIZACION. técnico-profesional

Configuraciones con resultado adverso: falta de acceso a empleo

14. familiares. SECUNDARIA. mérito. débiles. URBANA. PLAN. ACTIVA. especialización. técnico-profesional

15. familiares. secundaria. mérito. débiles. URBANA. plan. ACTIVA. especialización. técnico-profesional

16. familiares. secundaria. mérito. débiles. urbana. activa. especialización. técnico-profesional

El uso de abundante información de la cual seleccionar los fenómenos destacados es una dimensión inicial del tratamiento "holístico". La búsqueda de la presencia y ausencia de características y su interacción, y el hecho de poder contemplar las configuraciones en yuxtaposición, son procedimientos que añaden rigor al análisis de datos cualitativos.

El cuadro 3 muestra las cuatro configuraciones finales (numeradas 10,11, 12 y 13) para la búsqueda de empleo fructífera, y las tres configuraciones finales (numeradas 14, 15 y 16) para la búsqueda de empleo frustrada. Estas comprenden una tipología empírica de configuraciones de atributos en el grupo considerado.

A continuación se examinan la estrategia y características fructíferas, para luego compararlas con las frustradas.

El renglón 10 describe el patrón de individuos para quienes la presencia o ausencia de educación secundaria no influyó en el resultado. Estos individuos poseen los activos denominados "lazos débiles", es decir, información actualizada sobre el mercado laboral y las oportunidades existentes. Residen en el medio urbano, son capaces de sostener una búsqueda de empleo activa y proyectan capacitarse de algún modo para incrementar con ello su especialización comercializable y su empleabilidad. Les falta formación técnico-profesional y habilidades especializadas. Carecen de "lazos de mérito", es decir, de una trayectoria o reputación sólida que respalde la búsqueda de empleo por su cuenta. Y vienen de familias con fuertes lazos con el mercado laboral puesto que en ellas, al menos un adulto, tiene empleo regular e ingreso.
El renglón 11 muestra una configuración similar a la del renglón 10, en la mayoría de los atributos. Sin embargo, los vínculos de la familia o el hogar con el mercado laboral son débiles, ya que no hay adultos empleados. No obstante, el candidato posee enseñanza secundaria superior. Los estudios han demostrado que la educación comienza a tener efecto sobre el empleo cuando ésta es de nivel secundario superior (Banco Mundial, 1990). Esta observación sugiere que la presencia de calificaciones educacionales básicas es decisiva para los individuos provenientes de familias sin lazos fuertes con el mercado laboral.

El renglón 12 es una configuración de los que cuentan con buenos recursos en este grupo. Los individuos no se han adentrado, o quizá no todavía, en el mercado laboral para establecer "lazos de mérito", pero poseen una serie de otros recursos: antecedentes familiares sólidos frente al mercado laboral, educación secundaria, enseñanza técnico-profesional y especialización de alguna índole. Residen en el entorno urbano, poseen una base de información ("lazos débiles"), buscan empleo activamente y proyectan seguir capacitándose. Tienen buenas perspectivas.

El renglón 13 es la configuración que no se conforma a las características principales de la mayoría de las configuraciones exitosas ya descritas, lo que abre una perspectiva interesante. Representa un tipo de configuración que ha fortalecido su posición en el mercado laboral con respecto a un punto de partida original menos ventajoso para la búsqueda de empleo. Los individuos se asemejan al tipo anterior en que tienen "lazos débiles" o canales de información efectivos 
y despliegan gran actividad en la búsqueda de empleo, una combinación que se da en todos los patrones fructíferos. Estos pueden ser también atributos que se refuerzan mutuamente. Por lo demás, hay ausencia notoria de otras ventajas. Los individuos habían ingresado al mercado laboral sin haber cursado la enseñanza secundaria. Ante la falta de otras conexiones familiares con el mercado laboral, los "lazos débiles" se basaban probablemente en las relaciones existentes con el mercado laboral. No proyectaban seguir capacitándose. También residían en el medio rural.

La diferencia es que ahora poseen "lazos de mérito", es decir, han establecido una trayectoria en el mercado laboral basada en relaciones laborales estables. El tipo de conexión creada con el mercado laboral ha sido decisiva. Lo más probable es que haya dado origen al recurso especialización, puesto que no han tenido enseñanza técnico-profesional. El renglón 13 muestra que puede adquirirse un nivel adecuado de especialización comercializable mediante relaciones con el empleo productivo, incluso aunque el individuo no haya tenido antes la oportunidad de obtener escolaridad y capacitación formales. Una relación bien establecida con el mercado laboral puede tener por sí sola el peso suficiente para superar la ausencia de calificaciones formales y el capital social de las relaciones familiares. La combinación de lazos débiles y búsqueda de empleo muy activa se complementa con la especialización y los "lazos de mérito" establecidos con el mercado laboral, atributos decisivos para tener movilidad en el mercado laboral y evitar el desempleo crónico en esta configuración.

Desde una perspectiva práctica, el renglón 13 parecería ofrecer una fórmula maestra para los buscadores de empleo que comienzan con pocos recursos. Otro enfoque, sin embargo, sería el de examinar la gama de configuraciones fructíferas en yuxtaposición con las frustradas, y descubrir si sería posible responder con una amplia gama de intervenciones para hacer frente a las "ausencias" múltiples de recursos. Los patrones de atributos en la búsqueda de empleo que aquí se muestran representan diferentes configuraciones que dan origen a una variedad de procesos interrelacionados. En el caso de los patrones con una gama de recursos más generosa, las interrelaciones y los procesos de interacción tienden a reforzarse y potenciarse recíprocamente. En los patrones menos dotados, la ausencia múltiple de recur- sos y activos puede poner en peligro la eficacia de recursos que se dan en forma aislada.

$\mathrm{Al}$ examinar los patrones de aquellos en desempleo crónico, se observa que el renglón 14 se asemeja al renglón 11, excepto que en el primero hay ausencia de "lazos débiles". Esto sugiere que sin lazos débiles, la planificación y diligencia en la búsqueda de empleo por parte del individuo podrían ser dispersas y en último término improductivas. Esta conclusión es importante pues ilustra cómo la ausencia de un atributo ("lazos débiles") puede anular, por así decirlo, la efectividad de un recurso (ACTIVA) presente. En los grupos donde los recursos sociales y personales son menores en un sentido absoluto, los patrones de configuración particulares y las relaciones entre los componentes pueden tener una influencia determinante sobre el resultado de la búsqueda de empleo.

La presencia del factor residencia urbana parece asociarse sistemáticamente con la presencia de búsqueda de empleo muy activa. Los individuos de los renglones 14 y 15 residen en el entorno urbano, y, a semejanza de los individuos de los renglones $10,11 \mathrm{y}$ 12 que también lo hacen, este atributo parece facilitar la búsqueda de empleo muy activa. En las localidades urbanas donde la concentración de viviendas y lugares de trabajo es mayor, el transporte y sus costos no constituyen un obstáculo para la búsqueda de empleo como podría ser en las localidades rurales. Cabe también suponer que las redes de información son más densas en las concentraciones urbanas, lo que concede a los residentes urbanos una posible ventaja sobre los residentes rurales. No obstante, esto sugiere que la información generada por la densidad de contacto en las localidades urbanas puede no ser de la misma calidad que la generada por los "lazos débiles". Las configuraciones de los renglones 14 y 15 con resultado adverso, muestran la presencia de residencia urbana y una búsqueda de empleo muy activa pero combinadas con una falta de "lazos débiles" que generen información. Esto señala la importancia de poseer información precisa sobre el empleo y el mercado laboral, la que estuvo sistemáticamente ausente entre aquellos con desempleo crónico que carecían de "lazos débiles". El funcionamiento de bolsas de trabajo más amplias con patrocinio oficial ayudaría a salvar, al menos en parte, esta brecha que separa a los individuos que no poseen tales contactos. 


\section{VIII}

\section{Conclusión}

Las cuatro configuraciones eficaces y las tres ineficaces que aquí se analizan constituyen una tipología empírica de búsqueda de empleo en dos áreas del mercado laboral de Trinidad. Desde una perspectiva de política y de planificación, las tareas de investigación de esta índole pueden indicar dónde radican las debilidades en las configuraciones de recursos. Los recursos o las carencias de recursos de los individuos no deben considerarse en forma aislada, sino en el contexto de otros atributos influyentes que dan forma en conjunto al desenlace de la búsqueda de empleo.

Los resultados del estudio iluminan varios aspectos importantes del proceso de búsqueda de empleo. Ser residente urbano está asociado con tener proyectos de educarse o capacitarse más. En general, los individuos estaban dispuestos a adquirir especializaciones comercializables, debido posiblemente a la proximidad de los servicios y a los circuitos de información más densos. Ser residente urbano está asociado también con una búsqueda de empleo muy activa. En este grupo seleccionado que no tiene grandes recursos, una gran actividad en la búsqueda de empleo puede rendir muchos beneficios indirectos, como el de incrementar la toma de conciencia del individuo sobre la dinámica, la estructura y las reglas no escritas del mercado laboral. Sin embargo, esta actividad ha demostrado ser en buena medida improductiva para aquellos candidatos que carecían de una fuente de información más precisa sobre las esferas de oportunidades actuales y en cierne en las cuales centrar su búsqueda. Los lazos débiles que generan información "débil" desempeñan un papel fundamental en toda configuración de atributos. Entre los buscadores de empleo que carecen de recursos iniciales tales como enseñanza profesional, calificaciones educacionales básicas y "capital social" en el mercado del empleo, los "lazos de mérito" adquiridos paulatinamente a través del desempeño ocupacional en la economía formal pueden ser un activo compensador que garantice un estándar de competencia o especialización adquirida.

Las configuraciones de atributos que presentan ausencia múltiple de recursos y la marginación del mercado laboral apuntan a una situación en que los individuos se hallan en un patrón de subsistencia que depende, sobremanera, de redes informales y del ingreso irregular proveniente de la economía informal. En este grupo hay una acentuada diferencia de resultados entre aquellos que consiguieron establecer vínculos con el mercado laboral formal y aquellos que desempeñan actividades a nivel de subsistencia sin lograr el ingreso a los sectores formales. De estos datos es posible extrapolar que la asociación con el sector del empleo formal es más productiva de recursos -no sólo financieros - que promueven la movilidad social y económica. Por otra parte, la asociación con la actividad del sector informal produce beneficios económicos que bordean el nivel de subsistencia o de red de seguridad, pero que no conducen a una movilidad socioeconómica ascendente o lateral. Las configuraciones con enseñanza profesional y especialización estaban notoriamente ausentes de este grupo (con una excepción). Es probable que aquellos que poseían tales configuraciones cruzarán pronto el umbral del mercado laboral. Hay algunas medidas obvias para enfrentar las condiciones observadas en los grupos periféricos. Para aplicar enfoques innovadores es preciso identificar los atributos claves y sus interrelaciones, a fin de maximizar la eficacia de los programas.

(Traducido del inglés) 
Banco Mundial (1990): Informe sobre el desarrollo mundial 1990. Washington, D.C.

(1995): Trinidad and Tabago. Poverty and unemploymernt in an oil based economy, Report $\mathrm{N}^{\circ} 14382-\mathrm{TR}$, Washington, D.C., 27 de octubre.

Bourdieu, P. (1986): The forms of capital, en J.G. Richardson, ed., Handbook of Theory and Research for the Sociology of Education, Nueva York, Greenwood.

Bourdieu, P. y J.C. Passeron (1977): Reproduction: In Education, Society, and Culture, Beverly Hills, San Francisco, California, Sage Publications.

CEPAL (Comisión Económica para América Latina y el Caribe) (1997): La brecha de la equidad. América Latina, el Caribe y la cumbre social, LC/G.1954/Rev.1-P, Santiago de Chile, Publicación de las Naciones Unidas, $\mathrm{N}^{\circ}$ de venta S.97.II.G.11.

Gafar, J. (1998): Growth, inequality and poverty in selected Caribbean and Latin American countries, with emphasis on Guyana, Journal of Latin American Studies, vol. 30, $\mathrm{N}^{\circ} 3$, Londres, Cambridge University Press.

Granovetter, M.S. (1973): The strength of weak ties, American Journal of Sociology, vol. $78, \mathrm{~N}^{\circ} 6$, Chicago, Illinois, University of Chicago Press.

Granovetter, M. y C. Tilly (1988): Inequality and labor processes, en N.J. Smelser (ed.), Handbook of Sociology, San Francisco, California, Sage Publications.

Halsey, A.H., A.F. Heath y J.M. Ridge (1980): Origins and Destinations, Oxford, Reino Unido, Clarendon Press.

Henry, R. y J. Melville (1989): Poverty revisited, trabajo presentado a la Regional Conference on New Direction in Caribbean Social Policy, St. Augustine, Trinidad y Tabago, The University of the West Indies.

Kapferer, B. (1969): Norms and the manipulation of relationships in a work context, en J.C. Mitchell, ed., Social Networks in Urban Situations, Manchester, Reino Unido, Manchester University Press.

Lin, N., W.M. Ensel y J.C. Vaughn (1981): Social resources and strength of ties: Structural factors in occupational status attainment, American Sociological Review, vol. 46, $\mathrm{N}^{\circ} 4$, Washington, D.C., American Sociological Association.

Lin, J.C. , J.C. Vaughn y W.M. Ensel (1981): Social resources and occupational status attainment, Social Forces, vol. 59,
$\mathrm{N}^{\circ} 4$, Chapel Hill, North Carolina, University of North Carolina.

Marsden, P.V. y K.E. Campbell (1984): Measuring tie strength, Social Forces, vol. 63, $\mathrm{N}^{\circ}$ 2, Chapel Hill, North Carolina, University of North Carolina.

McKeever, M.(1998): Reproduced inequality: Participation and success in the South African informal economy, Social Forces, vol. $76, \mathrm{~N}^{\circ} 4$, Chapel Hill, North Carolina, University of North Carolina.

Naciones Unidas (1995): Informe de la cumbre mundial sobre desarrollo social, informe preliminar, Copenhague, Cumbre Mundial sobre Desarrollo Social (6 a 12 de marzo).

Neil, A. (1987): Voices from the hill: The steelband and its effects on poverty, stigma and violence in a community, mimeo.

Portes, A. y M. Castells (1989): World underneath: The origins, dynamics, and effects of the informal economy, en A. Portes, M. Castells y L. Benton, eds., The Informal Economy: Studies in Advanced and Less Developed Countries, Baltimore, Pensilvania, Johns Hopkins University Press.

Ragin, C.C. (1987): The Comparative Method: Moving beyond Qualitative and Quantitative Strategies, Berkeley, California, University of California Press.

(1994): Constructing Social Research, Thousand Oaks, California, Pine Forge Press.

Ramsaran, R.(1992): Growth, employment and the standard of living in selected Commonwealth Caribbean countries, Caribbean Studies, vol. 25, № 1-2, Río Piedras, Puerto Rico, Universidad de Puerto Rico, Institute of Caribbean Studies.

Rogozinski, J. (1994): A Brief History of the Caribbean: From the Arawak and the Carib to the present, Nueva York, Meridian.

Ryan, S. y T. Stewart, eds. (1995): The Black Power Revolution 1970: A Retrospective, St. Augustine, Trinidad y Tabago, University of the West Indies, Institute of Social and Economic Research.

Ryan, S., R. McCree y G.S. Bernard, eds. (1997): Behind the Bridge: Poverty, Politics and Patronage in Laventille, Trinidad, St. Augustine, Trinidad y Tabago, University of the West Indies, Institute of Social and Economic Research.

Valtonen, K. (1996): Bread and tea: A study of the integration of low-income immigrants from other Caribbean territories into Trinidad, International Migration Review, vol. 30, $\mathrm{N}^{\circ} 4$, Nueva York, Center for Migrant Studies of New York, Inc. 